\title{
ESTUDO DE CASO DA SUSTENTABILIDADE APLICADA NA GESTÃO DOS HOTÉIS DE CAMPO GRANDE, MS
}

CASE STUDIES OF APPLIED SUSTAINABILITY IN THE MANAGEMENT OF HOTELS IN CAMPO GRANDE, BRAZIL

\section{ESTUDIO DE CASO DE LA SOSTENIBILIDAD APLICADA EN LA GESTIÓN DE LOS HOTELES DE CAMPO GRANDE, MS}

MsC.,Esp., Grad. Maria Claudia Mancuelho Malta - UFMS minimalta@hotmail.com

Dr., MsC., Grad. Milton Augusto Pasquotto Mariani - UFMS miltmari@terra.com.br

\begin{abstract}
RESUMO
Tendo em vista que o meio ambiente, a sociedade e a cultura são um ativo para a atividade turística e, consequentemente, para os hotéis; e que há fragilidades na infraestrutura deste setor, este trabalho propõe analisar as práticas de sustentabilidade na gestão dos empreendimentos hoteleiros da cidade de Campo Grande, MS. Especificamente pretendeu-se: i) Correlacionar normas voltadas para sustentabilidade à gestão dos hotéis estudados da cidade de Campo Grande; ii) Identificar as práticas de sustentabilidade presentes na hotelaria de Campo Grande; iii) Caracterizar um perfil da sustentabilidade aplicada no setor hoteleiro de Campo Grande. Para tanto, foi realizada uma pesquisa exploratória, de abordagem qualitativa, em forma de estudo de caso, com entrevistas semiestruturadas aos gerentes de seis relevantes empreendimentos hoteleiros da cidade de Campo Grande, MS. As entrevistas foram transcritas e analisadas por meio da análise de conteúdo. Encontraram-se diversas práticas sustentáveis, tais como: equiparação salarial, acesso a portadores de deficiência, formas variadas de reutilização e reciclagem, utilização de produtos ecologicamente corretos e prática de lavagem das roupas de cama e toalhas apenas quando o hóspede solicitar. Caracterizouse um perfil da sustentabilidade na hotelaria da cidade de Campo Grande, qual seja: Sustentabilidade em estado inicial, porquanto falta informação acerca do conteúdo dela, ao passo que a maior quantidade de informações e práticas de sustentabilidade ocorre nos empreendimentos hoteleiros pertencentes a redes. Os gestores dos hotéis correlacionam a sustentabilidade apenas à dimensão ambiental, assim, precisam dirigir-se as demais dimensões presentes nela, de especial maneira a cultural.
\end{abstract}

PALAVRAS-CHAVE: Práticas de sustentabilidade. Empreendimentos hoteleiros. Campo Grande.

\section{ABSTRACT}

Given that the environment, society and culture are all assets for promoting tourism, and consequently, hotels, and there fragilities that exist in the infrastructure of this sector, this work analyzes the sustainability practices in the management of hotel establishments in the city of Campo Grande, in the Brazilian state of Mato Grosso do Sul. Specifically, it aims: i) to correlate standards geared towards sustainability in the management of the hotels studied, in Campo Grande; ii) to identify sustainable practices that exist in the hotel sector of Campo Grande, and iii) to characterize a profile of applied sustainability in the hospitality sector of Campo Grande. For this purpose, an exploratory study was carried out, with a qualitative approach 
in the form of a case study. Semi-structured interviews were carried out with the managers of six leading hotels in the city, and the interviews were transcribed and analyzed through content analysis. Various sustainable practices were found, such as: salary equalization, access for people with disabilities, different reuse and recycling methods, use of environmentally friendly products, and practices of washing linens and towels only when requested to do so by the hotel guest. A profile of sustainability were characterized in the hospitality of the city of Campo Grande namely: Sustainability practices are still in incipient form, due to a lack of information of the factors involved, with most information and sustainable actions being found in the hotels belonging to larger chains. The managers correlated sustainability only with the environmental dimension, highlighting a need to raise awareness of other dimensions, particularly the cultural dimension.

KEYWORDS: Sustainability practices. Hotel establishments. Campo Grande.

\section{RESUMEN}

Tomando en cuenta que el medio ambiente, la sociedad y la cultura son un activo para la actividad turística $y$, en consecuencia, para los hoteles, y que hay fragilidades en la infraestructura de este sector, este trabajo propone analizar las prácticas de sostenibilidad en la gestión de los emprendimientos hoteleros de la ciudad de Campo Grande, MS. Específicamente se intentó: i) Correlacionar normas dirigidas a la sostenibilidad en la gestión de los hoteles estudiados de la ciudad de Campo Grande; ii) Identificar las prácticas de sostenibilidad presentes en la hotelería de Campo Grande; iii) Caracterizar un perfil de la sostenibilidad aplicada en el sector hotelero de Campo Grande. Para ello fue realizada una investigación exploratoria, de abordaje cualitativo, en formato de estudio de caso, con entrevistas semiestructuradas a los gerentes de seis relevantes emprendimientos hoteleros de la ciudad de Campo Grande, MS. Las entrevistas fueron transcriptas y analizadas por medio de análisis de contenido. Se encontraron diversas prácticas sostenibles, tales como equiparación salarial, acceso de portadores de deficiencias, formas variadas de reutilización y reciclaje, utilización de productos ecológicamente correctos y práctica de lavado de ropa de cama y toallas únicamente cuando es solicitado por el huésped. Se caracterizó un perfil de la sostenibilidad en la hotelería de la ciudad de Campo Grande, a saber: sostenibilidad en estado inicial, ya que falta información acerca del contenido de la misma, mientras que la mayor cantidad de informaciones y prácticas de sostenibilidad ocurre en los emprendimientos hoteleros pertenecientes a redes. Los gestores de los hoteles correlacionan la sostenibilidad solamente a la dimensión ambiental, de modo que necesitan apuntar a las demás dimensiones presentes en ella, de especial manera la cultural.

PALABRAS CLAVE: Prácticas de sostenibilidad. Emprendimientos hoteleros. Campo Grande.

\section{INTRODUÇÃO}

A preocupação com o desenvolvimento sustentável levou a um dos maiores desafios que o mundo enfrenta neste novo milênio: fazer com que as forças de mercado protejam e melhorem a qualidade do ambiente com a ajuda de padrões baseados no desempenho e no uso criterioso de instrumentos econômicos, num quadro harmonioso de regulamentação. Esse novo contexto econômico caracteriza-se por uma rígida postura dos clientes, voltada à expectativa de interagir com organizações que sejam éticas, com boa imagem institucional no mercado e que atuem de forma ecologicamente responsável (TACHIZAWA; ANDRADE, 2008).

Assim sendo, o crescimento das organizações na atualidade propõe a adoção de medidas gerenciais pautadas na consciência ambiental e social, com finalidade de agregar vantagens competitivas e, consequentemente, financeiras. Nesse contexto, o turismo se apresenta como uma atividade que deve ser essencialmente voltada à sustentabilidade, pois, o entorno da localidade turística deve ser suficientemente atrativo para ser visitado e, paradoxalmente, seu desenvolvimento 
contribui para sua deterioração (LLULL et al., 2008, apud FONS et al., 2009). Desta forma, partindo do princípio que o meio ambiente e a cultura são os principais ativos do turismo, deve-se propor ferramentas de gestão que minimizem seus danos.

Seguindo este caminho as empresas hoteleiras também devem aderir ao conceito de sustentabilidade e se adequarem a ações socioambientais com o intuito de diminuir custos, criar diferencial, focalizar público e, principalmente, se autopromover, transformando em renda o patrimônio ambiental e natural. Apesar do segmento hoteleiro não exercer influência significativa sobre os problemas ambientais da atualidade, está diretamente ligado ao impacto ambiental, pois muitos hotéis estão situados em áreas de beleza natural, em cidades históricas e em regiões de delicado equilíbrio ambiental. Desta forma, o segmento hoteleiro não pode deixar de influenciar e ser influenciado pelo meio ambiente no qual está inserido (GONÇALVEZ, 2004). Além das influências dos impactos ambientais, o setor hoteleiro está diretamente relacionado aos impactos socioculturais das regiões nas quais os empreendimentos se localizam. A hotelaria funciona como receptora e disseminadora de cultura, tendo em vista que o turista traz e leva informações culturais.

A rede hoteleira da cidade de Campo Grande, capital de Mato Grosso do Sul, disponibiliza mais de 2.753 unidades habitacionais e 5.524 leitos. A taxa média de ocupação em 2009 foi de 50,2\% e a relação hóspede e unidade habitacional ocupada foi de 1,5 (FUNDTUR, 2011). A entrada de hóspedes registrada no ano de 2009 na capital foi de 344.633 mil, apresentando um aumento de $27,13 \%$ em relação ao ano de 2008. Esse turista tem uma permanência média de três dias na cidade. Segundo pesquisa, por meio da Ficha Nacional de Registro de Hóspedes (FNRH) em 2009, $59,6 \%$ das viagens para Campo Grande são por motivo de negócios ou convenções, 24,7\% vêm à capital fazer turismo e lazer e $16 \%$ por motivos diversos, confirmando Campo Grande como um destino de negócios e eventos. Outro indicador apontado na pesquisa é que 28,2\% desses hóspedes foram provenientes do Estado de São Paulo (FUNDTUR, 2011).

Para Oliveira e Sottili (2004), com o intuito de melhor explorar a atividade turística local, Campo Grande deve assumir e fortificar sua identidade turística. Deve caminhar como corredor turístico, pois algumas cidades não são necessariamente o destino final, mas sim um ponto de apoio para o prosseguimento da viagem. Nesse sentido a Fundação de Turismo de Mato Grosso do Sul (FUNDTUR) prevê estratégias de ação para o setor. Segundo a FUNDTUR o planejamento, a estratégia, a sustentabilidade, a promoção, a pesquisas e a cooperação público-privada são necessários para o desenvolvimento do turismo sul-mato-grossense.

Percebida, então, a importância e as características da sustentabilidade aplicada ao turismo e ao cenário hoteleiro, e que Campo Grande dispõe de turismo voltado aos negócios, aos eventos (SISGRAN, 2011) e que é corredor e ponto de apoio para o turismo de dois destinos turísticos importantes do Brasil - Pantanal e Bonito -, objetiva-se, nesta pesquisa, analisar a aplicação das práticas de sustentabilidade presentes na gestão dos empreendimentos hoteleiros da cidade de Campo Grande, mensurando, assim, seus pontos fortes e fracos. Desta forma, procurar-se-á responder: Como se manifestam as práticas de sustentabilidade na gestão dos empreendimentos hoteleiros da cidade de Campo Grande?

\section{SUSTENTABILIDADE E GESTÃO SUSTENTÁVEL}

Foi por volta do final do século XIX que ocorreram os primeiros sinais de preocupação com o planeta (COOPER et al., 2007). A escala produtiva elevou a quantidade de resíduos gerados, principalmente a partir da Revolução Industrial. A constatação de que os recursos naturais são esgotáveis e que é necessário levar em consideração o meio ambiente e a sociedade na produção de bens e serviço abriu caminho para a busca de soluções que contivessem o desenvolvimento com equilíbrio econômico, social e ambiental, o que se conceituou mais tarde como Desenvolvimento Sustentável. As evidências deixaram claro que sem o controle das questões relacionadas à sustentabilidade o ambiente físico e a qualidade de vida poderiam sofrer grandes perdas ou até chegarem à sua completa destruição (CARDOSO; TASCHNER, 2005).

A década de 1960 presenciou, então, os primeiros grandes movimentos no sentido de preocupações com o planeta em resposta ao período de rápido desenvolvimento do pós-guerra (COOPER et al., 2007). Com a divulgação do livro de Rachel Carlson, "A primavera silenciosa" (Silent 
spring), publicado em 1962, a humanidade foi alertada para os efeitos negativos dos agrotóxicos no ambiente natural. Na década de 1970 testemunhou-se a primeira conferência das Nações Unidas sobre o meio ambiente (COOPER et al., 2007). Nessa década, houve a divulgação do relatório do Clube de Roma, que alertava a humanidade para o esgotamento de recursos naturais, dos quais dependia a espécie humana, num prazo relativamente curto, caso continuasse o mesmo modelo de desenvolvimento (DIAS, 2008). A partir da Conferência de Estocolmo, em 1972, as nações começaram a estruturar seus órgãos ambientais e estabelecer suas legislações, visando ao controle da poluição ambiental. Também foram constatadas preocupações com racionalização de energia e busca de combustíveis mais puros. Em 1978 surge o primeiro selo ecológico, o Anjo Azul, destinado a produtos ambientalmente corretos (NASCIMENTO, 2008).

A inclusão do conceito de desenvolvimento sustentável - no mundo corporativo das empresas - foi definida pelo World Business Council for Sustainable Development (WBCSD), como o alcance do equilíbrio entre as três dimensões que balizam a sustentabilidade corporativa, que são: a econômica, a ambiental e a social. Para Cruz (2007), a estratégia organizacional com incorporação do desenvolvimento sustentável propõe a eliminação dos possíveis processos "insustentáveis". Para este autor, o referencial sustentável visa ao longo prazo, ao desenvolvimento de competências internas, à diversificação na forma de gerenciar os riscos envolvidos no negócio, à preocupação com a gestão social dos funcionários e com o impacto ecológico das estratégias empreendidas pela organização.

Por ser um conceito dinâmico, muitos esquemas de desagregação por dimensões foram propostos à sustentabilidade. Entretanto, no âmbito das organizações, o núcleo duro da sua contribuição para com o desenvolvimento sustentável passou a consistir em três dimensões: a econômica, a social e a ambiental. A redução das dimensões não implica perda ou abandono das outras dimensões, mas sim a concentração delas (BARBIERI; CAJAZEIRA, 2009). Percebe-se, pois, que a estrutura do trabalho analítico da sustentabilidade é ampla (COOPER et al., 2007). E quando se fala em desenvolvimento sustentável aplicado à corporação, torna-se necessária a inclusão das dimensões da sustentabilidade nos vários elos que formam a cadeia produtiva de uma empresa, desde a jusante até a montante de sua rede interempresarial (JAPPUR et al., 2008).

É interessante destacar o caráter harmonioso entre a proteção ambiental e o desenvolvimento social e econômico que a sustentabilidade propõe. O equilíbrio de todas as vertentes que compõem a sustentabilidade e a inovação é desafiador. Atendendo a uma das dimensões da sustentabilidade, a questão ambiental toma destaque no cenário empresarial. Para Barbieri (2007), a gestão ambiental é entendida como diretrizes e atividades administrativas e operacionais, tais como planejamento, direção, controle e alocação de recursos e outras realizadas, com o objetivo de obter efeitos positivos sobre o meio ambiente, quer reduzindo ou eliminando os danos ou os problemas causados pelas ações humanas, quer evitando que eles surjam.

A dimensão social consiste no aspecto social relacionado às qualidades dos seres humanos, como suas habilidades, dedicação e experiências, abrangendo os ambientes interno e externo da empresa (ALMEIDA, 2002). Para Barbieri e Cajazeira (2009), a sustentabilidade social, além de se pautar na saúde, na habilidade e na educação, deve, também, incluir criação de riquezas para a sociedade, sendo a confiança dos stakeholders internos e externos uma das características da organização social e, portanto, um dos fatores-chave para a sustentabilidade da empresa a longo prazo.

Sendo assim, melhorar as condições de vida das populações pobres, erradicando a fome e a miséria, eliminando crianças dos postos de trabalho, preservando o meio ambiente, tornará mais sustentável o desenvolvimento dessas localidades. E isso não é de interesse apenas do Estado, mas também das empresas privadas que buscam mercado (NASCIMENTO, 2008). Para Ashley (2005), a responsabilidade social de uma empresa se apresenta como compromisso que uma organização deve ter para com a sociedade, expresso por meio de atos e atitudes que a afetem positivamente. Ainda segundo Ashley, a responsabilidade social das corporações é mais importante nos dias atuais do que nunca, já que a ética afeta desde os lucros e a credibilidade das organizações até a sobrevivência da economia global.

A sustentabilidade econômica possibilita a alocação e a gestão eficiente dos recursos produtivos, bem como um fluxo regular de investimentos públicos e privados (BARBIERI; CAJAZEIRA, 2009). A dimensão econômica não inclui apenas a economia formal, mas também as atividades informais destinadas a indivíduos e grupos e que proporcionam aumento de renda monetária e de padrão de 
vida dos indivíduos (ALMEIDA, 2002). No âmbito empresarial, a dimensão econômica de que uma empresa precisa é dar lucro e ter seu valor de mercado aumentado, gerando riquezas para seus acionistas. Porém o conceito de lucro contábil, uma das linhas de resultados líquidos, apurados de maneira convencional, não é suficiente quando o que está em pauta é o desenvolvimento sustentável. Este deve levar em conta que o capital econômico é constituído de capital físico, financeiro e humano, além de outras formas de conhecimento amparadas pela legislação de propriedade intelectual, como as marcas e as patentes. Também não se pode deixar de mencionar que a contabilidade convencional também não registra os custos sociais e ambientais. Em síntese, é necessário que a empresa avalie os passivos ocultos para considera-los, a fim de obter resultado líquido referente à dimensão econômica da sustentabilidade (BARBIERI; CAJAZEIRA, 2009).

\section{SUSTENTABILIDADE APLICADA AO TURISMO E À HOTELARIA}

A Organização Mundial do Turismo (OMT) define turismo como sendo o "conjunto de atividades que as pessoas realizam durante suas viagens e estadas em lugares distintos do seu entorno habitual, por um período de tempo inferior a um ano, com fins de lazer, negócios e outros motivos não relacionados" (OMT, 2001). Servindo como válvula de escape para os indivíduos modernos, o turismo é consumido cada vez com mais intensidade. Atualmente o turismo vem se desenvolvendo e se caracterizando como uma atividade econômica relevante e singular, sendo responsável por: $9 \%$ do PIB mundial, 30\% das exportações de serviços mundiais e 1 de cada 12 empregos dos países em desenvolvimento (WTTC, 2012). Interessante não apenas para a economia mundial, esta atividade compõe 3,6\% do PIB Brasileiro (IBGE, 2011).

Para Assis (2003), o turismo é uma atividade complexa que relaciona, além dos elementos naturais e culturais das paisagens, diversos seguimentos da indústria, do comércio e dos serviços e, por isso, seu processo de expansão é tão veloz e dinâmico que já o reverenciam como o fenômeno mais promissor do século XXI. Segundo Cândido (2003), o turismo é uma atividade com ampla abrangência de atuação, buscando atingir alguns objetivos, além de recreação, lazer, descanso e diversão, tais como: contribuir para o crescimento e o desenvolvimento tanto econômico como social das comunidades envolvidas no processo; favorecer a evolução dos grupos humanos que residem em espaços de desenvolvimento turístico; proporcionar preservação de espaços naturais intocados ou parcialmente alterados, como também espaços culturais, históricos que apresentem vestígios de comunidades tradicionais.

A UNEP (2011) tem visto o turismo como um dos dez setores decisivos para a economia verde ou sustentabilidade, estando sob a luz dos holofotes da sustentabilidade, pois (a) sua produção e consumo tendem a ter lugar em áreas em que os recursos naturais ou artificiais são frágeis, (b) o ambiente e a cultura são usados como componentes principais do produto (COOPER et al., 2007). Complementando esta visão, Gilet, Orfila-Sintes e Chuliá (2008) asseguram que o meio ambiente constitui um dos principais ativos da indústria turística. Para esses autores, o turismo é uma atividade que requer um entorno que seja suficientemente atrativo para ser visitado, mas, paradoxalmente, seu desenvolvimento contribui para sua deterioração. Assim, é preciso considerar a questão da sustentabilidade no espaço em que se insere a atividade turística.

Ruschmann (2008) acredita que há falta de uma "cultura turística" que compreenda os danos causados por cada um dos turistas ao meio ambiente. Diante disso, estão sendo propostas outras formas de turismo, tais como o responsável, o alternativo, o ecológico e, mais recentemente, o turismo sustentável. Pretende-se deixar claro que o turismo sustentável não propõe apenas cuidados com a natureza local, mas também com a cultura local. Neste sentido, Corsi (2004) afirma que se tem, hoje, no turismo, uma grande expectativa para a melhoria de vida das comunidades, nas quais a integração turista e população seja tranquila e eficiente, com grandes acréscimos de conhecimentos para quem chega e ali permanece por algum tempo, assim como para aqueles que ali vivem.

O apelo cultural se ampliou e está presente desde o dito turismo de negócios às contemporâneas propostas de turismo ecológico, porque diferentes categorias de turistas, ao viajar, consomem gastronomia, artesanato, espetáculos artísticos, discos e livros, enfim, cultivam o hábito saudável de ser, fundamentalmente, viajantes com inquietações e desejos de consumo que vão muito além dos produtos industrializados tradicionais (CASTROGIOVANNI et al., 2001). Segundo Cooper et al. (2007), o turismo 
é um setor que pode produzir um impacto negativo muito grande nos ambientes culturais e naturais das localidades anfitriãs. Portanto o planejamento é fundamental e indispensável para o desenvolvimento turístico equilibrado e em harmonia com os recursos físicos, culturais e sociais das regiões receptoras, evitando, assim, que o turismo destrua as bases que o fazem existir (RUSHMANN, 2008).

Com base na definição de Bruntland, Cooper et al. (2007) conceituam o turismo sustentável como o turismo que vai ao encontro das necessidades atuais dos turistas e das regiões anfitriãs e, ao mesmo tempo, garante oportunidades para o futuro. É a gestão de todos os recursos, de tal forma que as necessidades econômicas, sociais e estéticas possam ser satisfeitas, mantendo-se, ao mesmo tempo, a integridade cultural, os processos ecológicos essenciais, a diversidade biológica e os sistemas de apoio à vida.

Assim sendo, o turismo sustentável propõe uma divisão mais justa de convivência entre o turismo e o meio ambiente, sem que nenhum dos parceiros venha a sofrer consequências danosas, procurando o equilíbrio entre a questão econômica e a conservação do meio ambiente (CORSI, 2004). Em complemento à definição de turismo sustentável, a Organização Mundial do Turismo (OMT), em conferência no ano de 2004, afirma que as diretrizes e as práticas gerenciais do desenvolvimento sustentável do turismo são aplicáveis a todas as formas de turismo e em todos os tipos de destinação, incluindo o turismo de massa e os diversos nichos de mercado turístico.

No Brasil estabeleceram-se, por meio do Conselho Brasileiro pelo Turismo Sustentável (CBTS), princípios que constituem a referência nacional para o turismo sustentável, são eles: respeitar a legislação vigente; garantir os direitos das populações locais; conservar o ambiente natural e sua biodiversidade; considerar o patrimônio cultural e os valores locais; estimular o desenvolvimento social e econômico dos destinos turísticos; garantir a qualidade dos produtos, dos processos e das atitudes; e estabelecer o planejamento e a gestão responsáveis (NBR 15401, 2006).

A sustentabilidade no turismo envolve, então, um processo de reconhecimento e responsabilidade. Reconhecimento de que os recursos utilizados para elaborar os produtos turísticos são caros e vulneráveis. Responsabilidade quando se fala em uso inteligente desses recursos por todos os interessados, desde os governos e os planejadores, até o setor que presta serviços, passando pelos turistas e moradores locais (COOPER et al., 2007). Portanto o desenvolvimento do turismo sustentável versa gerir os recursos naturais e humanos de modo a proporcionar prazer ao visitante e, ao mesmo tempo, beneficiar a localidade, minimizando, simultaneamente, os impactos negativos sobre a região e a população local.

Para Cooper et al. (2007), a sustentabilidade é um conceito muito presente nas discussões contemporâneas sobre o desenvolvimento do turismo. Ao mesmo tempo é um dos conceitos menos compreendidos e há de se percorrer um longo caminho até que haja um consenso em sua definição. Segundo o autor, tal como a definição geral de sustentabilidade, a definição de turismo sustentável também não alcançou maior sucesso. Para Cooper há centenas de variações sobre a definição de turismo sustentável. No entanto todas elas requerem considerações apropriadas ao bem-estar econômico, ambiental, sociocultural e político de longo prazo.

Mesmo com questionamentos sobre como integrar a sustentabilidade ao turismo, este já possui responsabilidade frente às questões ambientais e sociais. Segundo Swarbrooke e Horner (2002), em resposta a duas pressões, demanda dos consumidores por um turismo mais verde e regulação governamental, as organizações de turismo começaram a acenar para um vivo interesse pelo ambiente. No entanto, para esses autores, a atividade da indústria turística em relação à opinião pública sobre a sustentabilidade mais a conduz do que a reflete, ainda que muitas vezes em nível superficial.

Nesse sentido, Barroco (2004) afirma que o desenvolvimento do turismo, de uma forma sustentável, reclama a participação e a interação comunitária dentro dos mecanismos de aperfeiçoamento da ciência. Segundo ele, sem essa participação é quase impossível que haja desenvolvimento turístico. Consagrando a tendência da sustentabilidade aplicada ao turismo e, consequentemente à hotelaria, produto dele, Ruschmann (2008, p.17), expõe: "o turismo brando, ecológico, naturalista, personalizado e realizado em grupos pequenos de pessoas tende a caracterizar os fluxos turísticos do futuro".

Para promover a sustentabilidade, o turismo conta com um dos seus produtos: a hotelaria. Para Gonçalves (2004), o setor do turismo, em geral, e a hotelaria, em particular, têm a obrigação e a 
responsabilidade de fazer da ética ambiental parte integrante de suas metas organizacionais e gerenciais, já que o sucesso dos seus negócios depende em boa parte da "saúde" do meio ambiente.

Estudiosos do segmento turístico e hoteleiro, como Bissoli (2002), Ruschmann (2002), Araujo (2003) e Sassaki (2003), atestam a necessidade de cada vez mais estimular-se a formação profissional com foco no desenvolvimento de competências associadas ao mercado de trabalho, ao desenvolvimento das organizações turísticas e hoteleiras e, acima de tudo, sintonizadas pelo senso ético. Tal abordagem implica o redirecionamento do comportamento profissional, contemplando os valores e as normas que regem o bem comum, ou seja, a valorização, o respeito às diferenças, às minorias étnicas, às pessoas com necessidades especiais, visando à humanização do segmento turístico e hoteleiro (KANAANE; SEVERINO, 2006).

Autores como Abreu (2001), Amorim e Ramos (2003), De Conto (2005), Barbieri (2004), Campos, Selig e Cury (2001), Ferrari (2006) Souza (2004), Vieira e Hoffmann (2006), entre outros, apontaram benefícios auferidos pelos sistemas de gestão ambiental, uma das dimensões da sustentabilidade, pela correta utilização dos recursos água e energia, dos resíduos sólidos e dos efluentes líquidos, e pela responsabilidade dos fornecedores relativa à educação ambiental (SILVA; DE CONTO, 2007).

Como a hotelaria é um segmento de mercado em expansão que depende diretamente da atratividade exercida pelo meio ambiente saudável, urge agregar em seus valores, política e cultura, a responsabilidade ambiental. Os hotéis que adotam a postura sustentável procuram atitudes menos danosas ao ambiente por meio da reavaliação de suas ações e da conscientização de seus colaboradores. Essa postura é auferida por meio da otimização do uso dos recursos, do reaproveitamento e da reciclagem dos resíduos, maneiras simples de repensar o processo e tentar racionalizá-lo. Em função da contenção do desperdício, economizam-se os custos operacionais, crescem as oportunidades de mercado derivados das novas práticas ambientais, a imagem da corporação é fortalecida, além de causar um impacto positivo no moral dos empregados, aumentando o comprometimento dos clientes internos e o orgulho em ser parte da corporação (ENZ; SINGUAW, 1999).

Silva, Silva e Enders (2006) confirmaram as relações entre a gestão ambiental e o desempenho organizacional do setor hoteleiro. Segundo esses autores, as empresas hoteleiras que demonstram melhores níveis de desempenho organizacional tendem a usar mais as práticas de gestão ambiental. No âmbito econômico, os gestores do turismo e, consequentemente, da hotelaria, devem possuir conhecimento detalhado dos impactos econômicos e outros, derivados dessa atividade, uma vez que os turistas gastam seu dinheiro com uma variedade de mercadorias e serviços, tais como: transportes, alimentação, bebida, comunicação e entretenimento (BARROCO, 2004).

Priorizando o aspecto social, os gestores deverão respeitar a autenticidade sociocultural das comunidades anfitriãs, conservando seu patrimônio construído, patrimônio cultural e valores tradicionais, contribuindo para o entendimento mútuo e para a tolerância; para assegurar a viabilidade das operações econômicas de longo prazo, proporcionando benefícios socioeconômicos para todos os stakeholders, incluindo emprego estável, oportunidades de geração de renda e serviços sociais para as comunidades, contribuindo para a minimização da pobreza; fomentar a informação e a participação dos stakeholders, para garantir a ampla participação e a construção do consenso; manter a satisfação do turista em níveis elevados e garantir-Ihes uma experiência significativa, aumentando a sua consciência sobre as questões relativas à sustentabilidade (OMT apud CARDOSO; TASCHER, 2005).

Para Gonçalves (2004), a questão sustentável se torna a cada dia mais evidente no segmento de hospitalidade, tendo em vista as pressões dos consumidores, dos órgãos de regulamentação e das organizações não governamentais. Segundo pesquisa de Han, Hsu e Sheu (2010), os hóspedes, mesmo os que não estão diretamente ligados às práticas ambientais no seu cotidiano, preferem hotéis ambientalmente sustentáveis e, portanto, os gerentes devem apostar nas atitudes nesse sentido e anunciar as práticas verdes. Seguindo a mesma lógica, a Rede Accor, em pesquisa realizada com 6973 pessoas dos países Inglaterra, França, Alemanha, China, Brasil e Austrália no ano de 2011, $51 \%$ dos hóspedes levam em consideração se o hotel em que vão ficar, quando viajarem, atua de forma sustentável (PAULO, 2011).

Mas atingir o turismo sustentável é um processo que requer monitoramento constante dos impactos, introduzindo as medidas preventivas e/ou corretivas sempre que necessário. Nesse sentido, nos empreendimentos hoteleiros, as normas ISO, assim como a norma NBR 15.401, podem conduzir essas práticas. A norma da NBR 15.401 é a Norma Oficial Brasileira que prescreve quais 
requisitos os meios de hospedagem devem atender para serem considerados como praticantes de gestão sustentável, estabelecendo critérios mínimos específicos de desempenho em relação à sustentabilidade e permitindo a um gestor formular políticas e objetivos que levem em conta os requisitos legais e as informações referentes aos impactos ambientais, socioculturais e econômicos. Essa norma prevê uma série de práticas, dentre elas: cuidado com emissões, efluentes e resíduos sólidos; conservação e gestão do uso da água; eficiência energética; seleção e uso de insumos; saúde e segurança dos clientes e dos trabalhadores; qualidade e satisfação do cliente; trabalho e renda; cuidado com comunidades locais; cuidado com aspectos culturais; cuidados com as áreas naturais, flora e fauna; viabilidade econômica; cuidados com impactos luminosos e sonoros; paisagismos com espécies nativas; ações voluntárias; qualificação do profissional; incentivo da venda de artesanatos e produtos típicos; promoção da equidade étnica, social e de gênero; áreas devidamente sinalizadas para fumantes; o empreendimento deve dispor de um plano de negócios regularmente atualizado; informações básicas histórico-culturais e ecológicas da região onde está localizado; informações sobre a disponibilidade ou não de facilidades para atendimento a portadores de necessidades especiais e atendimento a emergências e acidentes (ABNT NBR 15401, 2006).

A revista Guia Quatro Rodas Brasil aderiu a critérios sustentáveis mais específicos, baseados nas regras do Leed - Leadership in Energy and Environmental Design, dos Estados Unidos; e do Green Star Accreditation, da Austrália, para selecionar hotéis sustentáveis. Dentre esses critérios estão: utilização de lâmpadas fluorescentes; chuveiros e vasos sanitários com baixo fluxo de água; recipientes fixos para xampu, condicionador e sabonete; equipamentos eletroeletrônicos com baixo consumo de energia; objetos que decoram os ambientes feitos com material reciclado; madeira de origem certificada de reflorestamento, azulejos ou pisos reciclados; sistema de reciclagem de lixo; reaproveitamento de lixo orgânico, como adubo; esgoto tratado; reaproveitamento da água da chuva na lavanderia, na piscina e na irrigação dos jardins; sistema de energia solar ou eólica; cartãochave para ativar o controle de luz e regular a temperatura do ambiente; projeto arquitetônico que aproveite a iluminação natural, com paredes envidraçadas e ambientes abertos e bem-ventilados; funcionários treinados para práticas sustentáveis; investimento na comunidade local; o hóspede escolhe se quer ter as toalhas e os lençóis trocados diariamente; utilização de alimentos produzidos na região. No ano de 2011 foram selecionados 43 estabelecimentos que possuíam características sustentáveis e que, portanto, foram marcados com o selo de sustentabilidade: um trevo de quatro folhas (Quatro Rodas, 2011). Portanto, utilizando-se de práticas sustentáveis, a empresa hoteleira pode propor a certificação que lhe garanta atestado sobre as ações aplicadas.

\section{PROCEDIMENTOS METODOLÓGICOS}

Tendo em vista a realidade socialmente construída e multidisciplinar que esta por trás do tema sustentabilidade, bem como do objetivo deste artigo, que trata de analisar a sustentabilidade nos empreendimentos hoteleiros da cidade de Campo Grande, o método qualitativo se tornou o mais adequado. A pesquisa qualitativa é um meio para explorar e para entender o significado que os indivíduos ou os grupos atribuem a um problema social ou humano. O processo de pesquisa envolve as questões e os procedimentos que emergem, os dados tipicamente coletados no ambiente do participante, a análise dos dados indutivamente construída a partir de particularidades para os temas gerais e as interpretações feitas pelo pesquisador a cerca do significado dos dados. O relatório final escrito tem uma estrutura flexível (CRESWELL, 2010, p. 26).

Quanto aos fins, essa pesquisa constitui-se como exploratória e descritiva. Ao mesmo tempo em que há pouco conhecimento acumulado sobre o assunto exposto, também se procurou expor características, mesmo que de forma induzida, de determinada população e fenômeno, traduzindose, respectivamente, em investigação exploratória e descritiva (VERGARA, 2007).

A estratégia de investigação utilizada foi o estudo de caso. Este é muito produtivo para estimular a compreensão e sugerir hipóteses e questões para a pesquisa (MATTAR, 2001). Para Martins e Theóphilo (2007, p. 61) , "(...) a estratégia de pesquisa estudo de caso pede avaliação qualitativa, pois seu objetivo é o estudo de uma unidade social que se analisa profunda e intensamente".

O levantamento da bibliografia foi realizado de acordo com os parâmetros estabelecidos por Severino (1996), que delimita o tema do trabalho a partir do problema, passando ao 
levantamento de documentação existente sobre o assunto. Nessa fase foram utilizadas fontes secundárias de informações.

Posteriormente à estruturação do referencial bibliográfico, passou-se à fase de desenvolvimento do instrumento de coleta de dados que, nesta pesquisa, foi um protocolo contendo questões norteadoras e indicadores com base nas normas que envolvem as dimensões de sustentabilidade, constituindo-se, portanto, de um roteiro semiestruturado para a entrevista, bem como para a observação direta. Para Yin (2010, p.106), "o protocolo contém o instrumento, mas também contém os procedimentos e as regras gerais a serem seguidas no uso do protocolo". Desta forma, utilizaram-se questões norteadoras aos atores da pesquisa, baseadas em Santos (2009) e adaptadas ao objeto de estudo. Agregaram-se novas reflexões e questões que possibilitaram interpretá-las e transformá-las em conteúdo aplicativo na pesquisa.

Quadro 01: Protocolos de estudo de caso

\begin{tabular}{|c|c|c|}
\hline Dimensão & Indicadores de Análise & Questões do Protocolo \\
\hline \multirow{10}{*}{ SOCIAL } & Responsabilidade social & \multirow{6}{*}{$\begin{array}{l}\text { Quais políticas e programas são desen- } \\
\text { volvidos para promover a melhoria nos } \\
\text { padrões de vida da sociedade? }\end{array}$} \\
\hline & $\begin{array}{l}\text { Equiparação salarial entre negros, pardos, } \\
\text { homens e mulheres com a mesma função. }\end{array}$ & \\
\hline & $\begin{array}{l}\text { Benefícios (alimentação, transporte, assistên- } \\
\text { cia médica e etc.). }\end{array}$ & \\
\hline & $\begin{array}{l}\text { Rotatividade de funcionários em relação à } \\
\text { média do mercado }\end{array}$ & \\
\hline & Índice de satisfação dos funcionários & \\
\hline & Índice de satisfação dos clientes & \\
\hline & Capacitação e atualização profissional & \multirow{4}{*}{$\begin{array}{l}\text { Quais ações e projetos são trabalhados } \\
\text { para promover a cultura local? }\end{array}$} \\
\hline & Apoio à diversidade de mão de obra & \\
\hline & $\begin{array}{l}\text { Programas e treinamentos para a redução de } \\
\text { acidentes de trabalho }\end{array}$ & \\
\hline & Programas de identidade cultural & \\
\hline \multirow{9}{*}{ AMBIENTAL } & Reciclagem & \multirow{5}{*}{$\begin{array}{l}\text { A estratégia ambiental da empresa } \\
\text { engloba quais fatores ligados à preser- } \\
\text { vação dos recursos naturais? }\end{array}$} \\
\hline & Tecnologias limpas e silenciosas & \\
\hline & Tratamento de afluentes líquidos & \\
\hline & Reaproveitamento de afluentes líquidos & \\
\hline & Produtos ecologicamente corretos & \\
\hline & Legislação ambiental & \multirow{4}{*}{$\begin{array}{l}\text { Como são implantadas as políticas de } \\
\text { racionalização dos recursos naturais? }\end{array}$} \\
\hline & Certificação pela norma ISO 14.000 & \\
\hline & Fontes alternativas de economia energética & \\
\hline & Racionalização de água e energia & \\
\hline \multirow{7}{*}{ ECONÔMICA } & Crescimento de resultados financeiros & \multirow{2}{*}{$\begin{array}{l}\text { De que forma as estratégias em sus- } \\
\text { tentabilidade impactam nos stake- } \\
\text { holders? }\end{array}$} \\
\hline & $\begin{array}{l}\text { Transparência nas ações próprias da em- } \\
\text { presa }\end{array}$ & \\
\hline & Pagamentos de salários & \multirow{3}{*}{$\begin{array}{l}\text { Qual a meta do hotel em propor sus- } \\
\text { tentabilidade? }\end{array}$} \\
\hline & $\begin{array}{l}\text { Aquisição de projetos adequados à sustent- } \\
\text { abilidade }\end{array}$ & \\
\hline & $\begin{array}{l}\text { Existência de pessoa ou cargo que analise a } \\
\text { dimensão sustentável do hotel }\end{array}$ & \\
\hline & Pesquisas sobre sustentabilidade & \multirow{2}{*}{$\begin{array}{l}\text { Quais as atitudes dos stakeholders } \\
\text { em relação às ferramentas de gestão } \\
\text { sustentável? }\end{array}$} \\
\hline & $\begin{array}{l}\text { Disposição em pagar mais pelo serviço am- } \\
\text { biental }\end{array}$ & \\
\hline
\end{tabular}

Fonte: Adaptado de Santos (2009). Elaborado pelos autores. 
Segundo Triviños (2008), na pesquisa qualitativa, em geral, não há preocupação pela quantificação da amostra. E, em vez da aleatoriedade, decide-se, intencionalmente, considerando uma série de condições, como, por exemplo, sujeitos que sejam essenciais segundo o investigador. Assim os hotéis foram selecionados de acordo com uma abordagem intencional, justificada pela intenção de se analisar três hotéis pertencentes a redes hoteleiras e três hotéis não pertencentes a redes hoteleiras. As entrevistas foram realizadas e gravadas nos próprios hotéis no mês de outubro de 2010. Os atores da entrevista foram os gerentes dos empreendimentos hoteleiros que tiveram disponibilidade em contribuir com a pesquisa.

De fundamental esclarecimento é o fato de que os nomes dos hotéis pesquisados serão mantidos em sigilo e serão nomeados de $H(A)$ a $H(F)$. Os hotéis pertencentes a redes hoteleiras serão os nomeados de $H(A), H(B)$ e $H(D)$. $E$ hotéis não pertencentes a redes serão chamados de $H(C), H(E)$ e $H(F)$.

Durante a entrevista procurou-se coletar dados também por meio da observação direta informal, que segundo Yin (2010) é frequentemente útil para proporcionar informação adicional sobre o tópico estudado. As entrevistas foram gravadas, transcritas e analisadas por meio da técnica de análise de conteúdo. Para Bardin (2009), a análise de conteúdo define-se como um conjunto de técnicas de análise das comunicações, marcado por uma grande disparidade de formas e adaptável a um campo de aplicação muito vasto: as comunicações. Segundo a autora, qualquer veículo de significados de um emissor para um receptor controlado ou não por este deveria poder ser escrito, decifrado pelas técnicas de análise de conteúdo.

Diante do exposto, foi montada uma planilha contendo as dimensões da sustentabilidade, seguida das questões norteadoras e de todas as respostas transcritas de cada um dos gerentes dos hotéis referentes àqueles assuntos. Optou-se por fazer as transcrições, pois se considerou de elevada importância para o entendimento da pesquisa. As transcrições foram realizadas com preocupação de manter a linguagem, dar opções por uma transcrição fonética e o uso da acentuação fonética conforme preceitos de Queiroz (1991).

A partir da análise dos dados da pesquisa empírica e das evidencias observáveis, formularamse interpretações que corroboraram com o referencial teórico sobre o tema e que poderão, em um próximo estudo, ser transformadas em hipóteses a serem confirmadas por meio de uma pesquisa que contenha amostra probabilística da população em estudo.

\section{TRATAMENTO E ANÁLISE DOS DADOS}

\section{ANÁLISE DA DIMENSÃO SOCIAL}

Dentre os empreendimentos hoteleiros pesquisados, os pertencentes às redes hoteleiras possuíam, em maior grau, algum tipo de ação ou projeto social quando comparados aos hotéis não pertencentes às redes hoteleiras. Estes últimos afirmam não possuir projetos específicos para esse fim. No entanto, ao indagar cada um dos itens que compõe as ações sociais aos empreendimentos hoteleiros não pertencentes a redes hoteleiras, percebeu-se que, mesmo em menor escala, há ações sociais.

Sobre projetos de responsabilidade social, os gerentes dos empreendimentos hoteleiros declararam:

H(A): Como o hotel (A) faz parte de uma rede, a gente trabalha com uma ação de responsabilidade social em nível de rede. Então, agora, em uma data específica, toda renda que for efetuada com relação às vendas de café da manhã do hotel, serão repassadas a uma instituição de alfabetização solidária.

H(B): Como a gente é rede (...) a gente tem uma ação que na verdade acontece no dia, não no dia das crianças, a nossa esse ano vai ser no dia 23 de outubro, que acontece com relação a feijoada. É assim, comemora-se o dia das crianças, chamam-se os clientes pra vir no dia da feijoada e uma parte é revertida, em dinheiro mesmo. A gente pega esse dinheiro, manda pra sede, e a gente tem uma instituição parceira... 


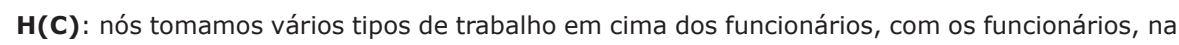
parte social. Fora que a própria diretoria participa de vários eventos sociais...

H(E): não, projeto nós não temos, até porque na verdade o hotel é uma empresa de pequeno porte. Na área social, eu acho que pela posse do hotel, se faz muito pouco. O que se faz são algumas doações através da posse do hotel para algumas entidades sociais, aí então, é o que é feito né, são doações financeiras mesmo.

$\mathbf{H ( F ) : ~ D e n t r o ~ d o ~ h o t e l ~ a ~ g e n t e , ~ r e c e n t e m e n t e ~ v e m ~ b u s c a n d o ~ e s t e ~ t i p o ~ d e ~ a c ̧ a ̃ o ~ m a s , ~ a l g u n s ~}$ programas. Programas sociais impostos até por órgãos oficiais, a contratação de menores, de deficientes. (...) dentro especificamente da área social, é contratação de menor aprendiz basicamente eu pensei que é uma imposição do nosso Ministério de trabalho.

Compreendeu-se, então, que, na dimensão social, destacam-se ações isoladas de doações a entidades filantrópicas entre os empreendimentos hoteleiros não pertencentes a redes. $E$ que projetos sociais apenas ocorrem em dois dos três empreendimentos hoteleiros pertencentes a redes. Isto posto, confirma-se também para a dimensão social o exposto para a dimensão ambiental evidenciada pelos autores Tachizawa e Andrade (2008), quando afirmam que os procedimentos associados às questões ambientais variam de acordo com o porte da organização. Assim, mesmo que de forma incipiente, ocorrem ações para minimização da pobreza, como propõe a dimensão social da sustentabilidade.

Quando questionados sobre equiparação dos salários dos funcionários, todos os seis empreendimentos hoteleiros pesquisados afirmaram possuir esta preocupação:

$\mathbf{H ( A ) : ~ A b s o l u t a m e n t e ~ o ~ m e s m o ~ s a l a ́ r i o , ~ m e s m a ~ c a r g a ~ h o r a ́ r i a , ~ m e s m o ~ s a l a ́ r i o . ~ N a ̃ o ~ t e m ~ n e n h u m ~}$ tipo de discriminação.

H(B): Mas aí tudo amarrado com um contrato de gestão. Então, isso não tem nada a ver com gênero, se é mulher ou se é homem, porque tanto faz.

$\mathbf{H ( C ) : ~ O ~ s a l a ́ r i o ~ a q u i ~ d o ~} H(C)$ é classificado por função. Indistinto de sexo, raça...

H(D): Os salários são por função, não interessa ser branco, negro, mulher.

H(E): O salário é determinado pela função que pessoa exerce, então independente de raça, credo ou mesmo do gênero, o salário é o mesmo.

Sendo, então, unânimes em afirmar que não há desigualdades com relação a sexo, raça ou ideologias para contratação ou discussão salarial. Um dos gerentes mencionou que há preocupação em contratação de portadores de necessidades especiais, conforme exposto pelo gerente do hotel (F). Outro, por sua vez, informou que o seu hotel está isento pela lei de contratar funcionários portadores de necessidades especiais, tendo em vista sua quantidade de funcionários. Ainda em relação a deficiências físicas, em pesquisas secundárias através dos sites dos hotéis; bem como pela observação direta, percebeu-se que todos os empreendimentos hoteleiros possuem acesso a portadores de deficiência física ou cadeirantes.

Sobre os benefícios, a atualização profissional e os treinamentos destinados aos colaboradores, os gerentes disseram aplicar o que a legislação os obriga. Cultiva-se, também, na sua maioria, algum tipo de treinamento ou atualização profissional destinado à função exercida pelo funcionário. Percebe-se que os empreendimentos hoteleiros de rede, em maior grau, dedicam-se a especializar seus funcionários, considerando as imposições da marca.

Quando questionados sobre prevenção de acidentes no trabalho, percebeu-se que estas ações ocorrem em forma de orientações nos treinamentos, portanto, ação preventiva.

$\mathbf{H ( A ) : ~ N a ̃ o ~ e x i s t e ~ p o r q u e ~ a ~ l e i ~ n a ̃ o ~ d e t e r m i n a . ~ N a ~ v e r d a d e , ~ n o ́ s ~ t e m o s ~ u m ~ n u ́ m e r o ~ d e ~ c o l a b o r a d o r e s ~}$ pequeno aqui no hotel que não é exigido por ela, por essa legislação. Isso vai depender do número de colaboradores que o hotel possui. Então, nós temos aqui 24 colaboradores no quadro, então nós estamos isentos de ter essa comissão.

H(B): Redução de acidente com certeza tem, porque todas as pessoas que trabalham, por exemplo: camareiras, em específico, tem que trabalhar com luva, tem que saber manipular produto químico $[. .$.$] tem que ter todo o procedimento [...] a cozinha tem que ter todas as luvas$ que é para cortar carne; para não cortar a mão, tem que estar com o cabelo preso... 
H(C): [...] agora mesmo nós estamos contratando uma psicóloga para fazer todo um trabalho com os funcionários. Então assim, nós temos sim essa preocupação..

Sobre a rotatividade dos funcionários, dois empreendimentos hoteleiros, dentre os não pertencentes a redes, afirmam que praticamente não há rotatividade e que a política dos hotéis é demitir apenas em último caso. Os demais empreendimentos hoteleiros pesquisados garantem ter rotatividade normal.

Todo o exposto sobre os funcionários mostrou que os empreendimentos hoteleiros afirmam cumprir com a legislação trabalhista. O que também corrobora com a avaliação positiva acerca da dimensão social da sustentabilidade, mesmo que os gerentes, de forma geral, não identifiquem essa correlação.

Analisando o repasse de informação sobre a sustentabilidade por parte da gestão do empreendimento hoteleiro para com os funcionários e hóspedes, que caminham por todas as dimensões, percebeu-se que, dentre os gerentes que visualizam alguma prática de sustentabilidade na sua gestão, dois gerentes dos hotéis pertencentes a redes acreditam no trabalho de conscientização da gestão voltada à sustentabilidade do empreendimento sobre seus funcionários e/ou hospedes.

O gerente do $\mathrm{H}(\mathrm{C})$, no entanto, mesmo acreditando nas práticas sustentáveis, declarou em determinado momento que "(...) isso já tinha que ser uma coisa automática da pessoa" e em outro repassou a seguinte frase do diretor do empreendimento hoteleiro "a gente tem que estar sempre passando pros funcionários; incentivar ele a fazer alguma coisa que traz benefícios para o hotel, só que também que traz benefícios pra vida dele". Assim, este empreendimento hoteleiro parece se importar com o conceito, sem, no entanto, possuir consciência plena sobre ele. Talvez até por não fazer parte de uma rede que tenha esse conceito assimilado e difundido.

Isto mostra que, conforme explanado pelos autores Enz e Singuaw (1999), a postura sustentável procura atitudes menos danosas ao meio ambiente por meio da conscientização de seus membros, causando um impacto positivo no moral de seus empregados, aumentando o comprometimento e o orgulho em fazer parte da corporação. Assim como informam aos clientes sobre a sustentabilidade, aplicando o que foi dito por Swarbrooke e Horner (2002) que afirmam que a atividade turística em relação à opinião pública, mais a conduz do que a reflete, evidenciando, pois, que as práticas de sustentabilidade aplicadas no setor hoteleiro informam e comprometem os seus stakeholders.

Com relação ao índice de satisfação dos funcionários, duas das empresas de redes possuem pesquisa para medi-las. Os demais gerentes afirmam não possuir instrumentos para medir a satisfação dos funcionários, apesar de alguns gerentes afirmarem possuí-las em conversas informais.

Os dois empreendimentos hoteleiros pertencentes a redes hoteleiras, que se mostraram mais comprometidos com a sustentabilidade em outros pontos abordados, também possuem formas mais adequadas e fidedignas para apontar o nível de satisfação dos funcionários. O que condiz com o conceito da dimensão social da sustentabilidade, que prevê benefícios e sucesso para os colaboradores.

Os gerentes dos empreendimentos hoteleiros pesquisados, em sua maioria, não souberam apontar projetos com algum tipo de incentivo cultural. Apenas o gerente do empreendimento hoteleiro (D) qualificou a ação de informação da recepção como uma forma de divulgar a cultura local. Logo, percebe-se que há pouca informação quanto às práticas culturais que podem ser praticadas pelos empreendimentos hoteleiros. O foco cultural ainda é bem distante e não há associação entre a cultura e a sustentabilidade e, por conseguinte, entre a cultura e a geração de lucro advinda dela. Durante as entrevistas, a alimentação e a decoração do hotel não foram sequer lembradas como elementos de difusão da cultura local.

No entanto, em observação e análise de documentos, concluiu-se que apenas dois dos seis empreendimentos hoteleiros pesquisados se preocupam em propagar a culinária local, sendo um deles pertencente a uma rede hoteleira, $H(A)$, e o outro não, $H(F)$. Outra observação da pesquisa ocorreu quanto à decoração dos ambientes dos empreendimentos hoteleiros. A sustentabilidade prevê que a decoração seja também atrelada à cultura local, no caso, pantanal ou pecuária. Assim, percebeu-se de forma discreta que três dos seis empreendimentos hoteleiros utilizam alguma forma de decoração neste sentido, sendo dois deles não pertencentes a redes. Observouse também que em nenhum dos empreendimentos hoteleiros há venda de produtos típicos e que não há paisagismo com espécies da flora local. 
Assim, a questão cultural inserida na dimensão social da sustentabilidade ainda não parece ser considerada um ativo para os empreendimentos hoteleiros de Campo Grande. O que comprova que, mesmo os empreendimentos hoteleiros pertencentes a redes hoteleiras dessa cidade, que parecem possuir maior grau de informação sobre a sustentabilidade, negligenciam o que a norma NBR 15401 prescreve sobre possuir e transmitir informações básicas históricas e ecológicas da região na qual está localizado; bem como de incentivar a venda de artesanatos locais e produtos típicos e o paisagismo das espécies locais.

Observa-se, então, que as preocupações sociais, mesmo que em pequena escala, existem, sendo pautada principalmente na legislação, a responsabilidade social nos empreendimentos hoteleiros não deixa de ser promovida em maior escala e de forma mais organizada pelas redes hoteleiras em forma de projetos nacionais. Não se pode deixar de mencionar que algumas das ações sociais advêm da preocupação ambiental, como, por exemplo, a doação de material reciclável. Isto se mostra, portanto, na exposição da próxima dimensão.

\title{
ANÁLISE DA DIMENSÃO AMBIENTAL
}

Um dos fatores de atratividade do setor hoteleiro é o próprio ambiente ao qual está inserido. Nesse sentido, a preocupação com o meio ambiente é inevitável para uma estratégia de longo prazo dessas empresas. Desta feita, os empreendimentos hoteleiros pesquisados afirmaram possuir algumas ações voltadas a esse fim. Mesmo que alguns não possuam projetos para esse fim, de forma simplista as estratégias ambientais estão presentes em ações que vislumbram economia de recursos. Mais uma vez, os empreendimentos hoteleiros pertencentes a conhecidas redes hoteleiras mostraram maior conhecimento acerca do assunto.

\begin{abstract}
H(A): nós temos uma carta ambiental. Essa carta ambiental mensura todos os indicadores, de tudo que o hotel trabalha dentro da área ambiental. Então nosso hotel dedica-se ao meio ambiente e essas são as prioridades desse hotel, desta unidade com relação ao meio ambiente, e onde isso impacta a nossa gestão. A gente tem níveis de energia, água, resíduos, ozônio, águas residuais, biodiversidade, informação e sensibilização e controle ecológico. Então são esses os princípios que a gente trabalha aqui dentro desse hotel, e cada um deles, claro tem uns itens específicos.
\end{abstract}

\begin{abstract}
H(B): A gente tem o outro que é com o hóspede que é o 'planet for the planet', que é para o pessoal, que a gente informa, deixa na recepção que se as tolhas forem reutilizadas, ou seja, o hóspede foi e reutilizou, cada 05 toalhas reutilizadas é uma árvore plantada. Então a gente reverte a economia dessas toalhas para uma instituição, porque a gente não entende disso, e eles fazem o reflorestamento.
\end{abstract}

H(E): Não, nós não temos nenhum projeto. Talvez pelo nosso ramo. (...) como falei pra você, trabalho com serviço; não trabalho com produto em si. Então, projeto mesmo não há nenhum não.

$\mathbf{H}(\mathbf{F})$ : É difícil te falar, porque nós não temos projetos de sustentabilidade na área de serviço dentro do hotel então, não tem como te falar essa diferença, nós vendemos um serviço só.

Quando perguntados sobre reciclagem, apenas o empreendimento hoteleiro (E) afirmou não possuir nenhum tipo de reciclagem. Os demais falam em reaproveitamento de papéis e procedimentos para coleta seletiva de lixo. O reaproveitamento do óleo de cozinha também foi uma questão lembrada dentre as atividades ambientais desempenhadas por alguns empreendimentos hoteleiros. Há doações desse item, assim como de lixo reciclável, para empresas terceirizadas. Houve também afirmação por parte de um gerente que o valor da reciclagem é revertido para festas entre funcionários no final do ano. Isto posto, demonstra-se a inter-relação existente entre as dimensões da sustentabilidade.

Sobre produtos ecologicamente corretos, a maioria dos gerentes disse possuir preocupação em adquiri-los. Dentre os três empreendimentos hoteleiros não pertencentes a redes, dois afirmaram que não há preocupação nesse sentido.

A energia e a água são preocupações em todos os empreendimentos hoteleiros pesquisados. Todos estes empreendimentos possuem fontes alternativas de energia, como a energia solar ou gerador. Alguns apostam em bloqueadores de energia e poços artesianos para gerar economia. 
H(B): A gente trabalha com energia verde. A gente tem um gerador que entra nas horas de pico. A gente tem essa preocupação tanto por conta de custos também, e isso reverte dinheiro, quanto menos custos, mais dinheiro sobra, como é o caso numa operação.

H(C): Temos o teto solar, e nós temos um gerador. Acho que toda empresa agora é obrigada a ter isso já. Isso não é mais uma coisa que você quer, além de você querer, já é uma obrigação porque hoje se tornou muito importante a preservação.

H(D): Só quando tem queda que a gente tem gerador.

H(E): Ah, nos apartamentos existem um bloqueador de energia, então, a partir do momento que hóspede entra no apartamento, ele utiliza o próprio chaveiro da porta como desbloqueador de energia. Então, é uma forma de que, quando essa pessoa sai do apartamento, alguns segundos depois, questão de 30; 40 segundos depois, toda a instalação elétrica é cortada, exceto o do frigobar. Então, é a forma de minimizar também um pouquinho o consumo de energia.

H(F): [...] 48\% da energia pública e, 52\% é gerado por gerador próprio. Então a energia basicamente. Água, temos $100 \%$ de água de poços artesianos nossos...

Sobre padrões e normas, uma das empresas hoteleiras contatadas possuía ISO 14001 e outras duas estão em processo de implantação de certificações. As demais, por meio dos gerentes, não alegaram nenhuma preocupação em possuir certificação em normas ambientais.

Ademais, percebe-se que na grande maioria dos empreendimentos hoteleiros pesquisados não há monitoramento constante dos impactos causados pelas ações não sustentáveis e muito menos atuações preventivas ou corretivas. Não há indicadores que constituam uma carta de navegação, como aborda Guimarães e Feichas (2009). Apenas por esse ponto, evidencia-se o caráter inicial da questão sustentável nos empreendimentos hoteleiros da cidade de Campo Grande.

Observou-se que o setor hoteleiro possui algumas ações específicas, tais como os programas de reutilização de toalhas e roupas de cama por parte dos hóspedes que utilizam os quartos em um período maior que um dia. Sobre isso, nota-se que dois dos seis empreendimentos pesquisados não aderem a esse tipo de solução sustentável, $H(E)$ e $H(F)$. Interessante salientar que ambas as empresas hoteleiras não pertencem a redes hoteleiras.

Nota-se, dentre os empreendimentos hoteleiros pesquisados, que há maior grau de atuação ambiental nas empresas hoteleiras pertencentes a redes. Talvez por estes estarem vinculados a maiores informações sobre sustentabilidade ambiental, já que se notou maior domínio sobre o assunto por parte de seus gestores. Mesmo com maior informação, estes empreendimentos hoteleiros ainda estão no início das implantações de certificações ambientais. Assim sendo, ainda há um grande percurso a se percorrer para que a sustentabilidade ambiental nos empreendimentos hoteleiros de Campo Grande possa, ao menos, amadurecer.

Sabendo que as preocupações com meio ambiente por parte dos empreendimentos pesquisados ainda estão intimamente ligadas à economia e à legislação, a análise da percepção dos gerentes dos empreendimentos hoteleiros pesquisados sobre a dimensão econômica se faz indispensável para compor o tripé que propõe a sustentabilidade.

\section{ANÁLISE DA DIMENSÃO ECONÔMICA}

Dentre os gerentes dos empreendimentos hoteleiros pesquisados, observou-se que metade acredita no impacto econômico positivo para o hotel advindo de ações sustentáveis. Os demais não conseguiram mensurar os impactos econômicos gerados pelas ações sustentáveis por não possuírem projetos nesse sentido ou por não conseguirem medir as ações aplicadas:

H(A): Os clientes pagam a menos por esses serviços! Como a gente percebe certa economia; economia de produtos químicos, economia de água, economia de energia elétrica, isso tudo reflete na tarifa do hotel. Então, nós temos tarifas menores porque nós temos programas de sensibilização ambiental.

H(B): A partir do momento que você consegue reciclar, consegue, tipo dá alguma finalidade, diminuir gastos e custos desnecessários, e poluir menos, gastar menos. [...] isso reverte-se em dinheiro. Quanto menos custos, mais dinheiro sobra! 
H(C): Tudo o que você faz, de repente você não consegue ver o resultado na hora, o resultado você vê em longo prazo.

H(D): Essa reciclagem de material, na verdade a gente faz. Normalmente é reservado na área de funcionário. Agora no caso da toalha a gente não sabe como é. No caso da água não tem como medir porque é por poço artesiano...

H(E): [...] hoje, se fala muito sustentabilidade, fala bastante, mas muita coisa fica no papel. Talvez pelo nosso ramo, não trabalhamos com projeto algum.

Desta feita, confirma-se que não há contabilidade formal com relação às práticas sustentáveis que os empreendimentos hoteleiros de Campo Grande exercem. O que vai contra as orientações de Barbiere e Cajazeira (2009) quando abordam que é necessário que a empresa avalie os passivos ocultos para obter o resultado líquido referente à dimensão econômica da sustentabilidade.

Mesmo não sendo feito de forma formal, a economia conseguida com a aplicação de práticas sustentáveis é um dado que pode ser percebido pelos gestores, até mesmo por meio das ações dos seus funcionários. Neste sentido, alguns gerentes mencionaram sobre o impacto econômico da sustentabilidade sobre seus colaboradores.

A sustentabilidade também pode ser mensurada por meio da imagem gerada por suas ações aos seus consumidores. Ou seja, as atitudes positivas por parte dos clientes frente às práticas sustentáveis podem ser percebidas pelos gestores e transformadas em vantagens competitivas por eles utilizáveis. No entanto, nesse requisito, houve impasse na pergunta com relação à sensibilidade dos clientes à questão sustentável. A metade dos gestores acredita que os hóspedes valorizam as práticas sustentáveis. A outra metade, no entanto, não consegue medir a valorização dos hóspedes frente às ações de sustentabilidade aplicadas nos hotéis, até por não possuírem projetos nesse sentido.

Importante salientar que se não conseguem acreditar que o cliente é capaz de valorizar a sustentabilidade, também não acreditarão na diferenciação advinda destas práticas. E, portanto, não apostarão na gestão voltada para a sustentabilidade nesse setor, até que consigam mensurar a economia financeira ou que haja intervenção da legislação.

Sobre pesquisa e gerência designada a projetos sustentáveis, obteve-se a resposta de que não houve pesquisa na área de sustentabilidade em nenhum dos empreendimentos hoteleiros pesquisados. Notou-se também que os gerentes são os responsáveis pela gestão do hotel como um todo e, portanto, caso haja projeto sustentável, serão eles próprios os responsáveis por tratar desse assunto junto aos demais funcionários.

\section{CONCLUSÃO}

Havendo a comparação entre as normas que envolvem sustentabilidade e as ações dos hotéis, evidenciou-se que as práticas de sustentabilidade utilizadas são incipientes e isoladas, determinadas, principalmente, por leis ou por economia comprovada sem grandes esforços. Assim, o perfil da sustentabilidade aplicada ao setor hoteleiro de Campo Grande, MS, mostra que ela ainda está em início. Desta forma, falta informação acerca do que realmente prevê a sustentabilidade, ao passo que a maior quantidade de informações e, portanto, de práticas de sustentabilidade, ocorre nos empreendimentos hoteleiros pertencentes a redes. Correlacionada pelos gestores dos hotéis apenas à dimensão ambiental, a sustentabilidade nos hotéis de Campo Grande precisa se dirigir às demais dimensões presentes na sustentabilidade, de especial maneira, ao cultural.

Os pontos fortes das práticas de sustentabilidade encontrados na gestão dos empreendimentos hoteleiros pesquisados foram: equiparação salarial, acesso a pessoas com deficiência, formas variadas de reutilização e reciclagem, utilização de produtos ecologicamente corretos e prática de lavagem das roupas de cama e toalhas apenas quando o hóspede solicitar. Assim como os pontos fracos ficaram evidentes quando o fator cultural foi negligenciado, quando os gerentes expuseram não possuir pesquisas e certificações sobre a sustentabilidade ou quando afirmaram não contabilizar as ações voltadas à sustentabilidade de suas empresas hoteleiras.

As práticas culturais, mais negligenciadas dentre as dimensões da sustentabilidade, são essenciais para o turismo e, portanto, necessitam, urgentemente, de mais atenção. Não há dúvidas de que a 
gestão da cultura local mostrará resultado para o setor. Mesmo que o público alvo seja o turista de negócio, em posse das manifestações de cultura local, poderá retornar junto com a família, estando em férias, ou mesmo divulgar ou indicar a cidade aos conhecidos. Recomenda-se, pois, que haja venda de produtos típicos dentro dos hotéis, que haja interesse na divulgação dos pontos turísticos, que a decoração dos hotéis seja voltada ao Pantanal, à pecuária, à cultura indígena, à pesca e ao ecoturismo de Bonito. Do mesmo modo, que a flora local seja utilizada para o paisagismo dos empreendimentos hoteleiros.

Tendo em vista que o bem natural se constitui no principal ativo do turismo, os passivos ocultos e as externalidades negativas também carecem ser mensurados na contabilidade formal dos hotéis. Em Campo Grande essa atividade está sendo descuidada e, assim, merece esmero. A correta gestão dos produtos do turismo local, levando em conta os bens naturais, seja eles o meio ambiente, a cultura ou a sociedade, é essencial para a conservação do setor turístico.

Varias informações com relação à pesquisa empírica adotada neste estudo replicou informações teóricas contidas ao longo do texto sobre sustentabilidade. O porte da organização, por exemplo, determina o grau de informação acerca da sustentabilidade. Quanto maior a organização, maior será a informação e as ações sobre do assunto. Da mesma forma, o estudo também replicou que a compreensão sobre a sustentabilidade ainda é escassa para os gestores. Ou seja, muitos gestores não compreendem todas as dimensões envolvidas no tema sustentabilidade. Especificamente neste estudo, percebeu-se que os gerentes dos hotéis notavam, em maior grau, a dimensão ambiental da sustentabilidade, as outras dimensões eram pouco assimiladas. O impacto positivo no moral dos empregados também foi outra questão comprovada, conforme a teoria apresentada. Além de absorver as práticas de sustentabilidade no seu dia a dia, os funcionários relatam, segundo os gestores dos hotéis, também manifestarem-se felizes em pertencer a uma empresa que apoia o legado que a sustentabilidade propõe. Também se notou claramente, por meio das falas dos entrevistados, que as atitudes dos hóspedes com relação à sustentabilidade estão sendo alteradas. Muitos dos consumidores já estão advertindo a gestão do hotel sobre as questões que envolvem a sustentabilidade. No entanto também houve evidências que mostraram que nem sempre aqueles que detinham informação sobre a sustentabilidade aderiam às suas práticas.

Não há dúvidas de que a informação sobre a sustentabilidade seja o começo para o envolvimento concreto da população. E neste sentido crê-se, do exposto, que as empresas hoteleiras tendem a conduzir, muito mais do que refletir, a opinião dos hóspedes sobre a sustentabilidade. Afinal, os hotéis que possuem maior número de práticas voltadas à sustentabilidade também são os hotéis que os gerentes visualizam uma resposta positiva dos hóspedes sobre o assunto. Assim, sabendo que a sustentabilidade é um caminho de mão dupla, em que os empreendimentos informam e influenciam os clientes ao mesmo tempo em que são exigidos por eles, sugere-se que as políticas públicas acelerem o processo que legitima a gestão sustentável nos empreendimentos hoteleiros.

Constituindo-se então em uma importante carta de navegação aos gerentes dos hotéis que pretendem fortalecer sua gestão, bem como às políticas públicas que vislumbram estipular um caminho rumo à sustentabilidade, as implicações gerenciais trazidas por este estudo constituemse importantes contribuições não só para o setor hoteleiro e para as políticas públicas, mas também à teoria da sustentabilidade aplicada ao setor hoteleiro. Recomenda-se, portanto, que esta pesquisa seja generalizada agora em nível populacional e que seja, assim, elaborada uma pesquisa com amostra probabilística de hotéis na cidade de Campo Grande; e que sejam utilizadas as interpretações desta pesquisa como hipóteses. Outra recomendação é expandir essa pesquisa para outras localidades - até mesmo por existir diferentes características turísticas - de modo que haja comparação da sustentabilidade aplicada nos empreendimentos hoteleiros de várias cidades e de vários tipos de turismo.

\section{REFERÊNCIAS}

ABNT, Associação Brasileira de Normas e Técnicas. NBR 15401: Meios de hospedagem - Sistema de gestão da sustentabilidade - Requisitos. Rio de Janeiro, 2006.

ALMEIDA, F. O bom negócio da sustentabilidade. Rio de Janeiro: Nova Fronteira, 2002. 
ASHLEY, P. A. Ética e responsabilidade social nos negócios. São Paulo: Saraiva, 2005.

ASSIS, L. F. Turismo Sustentável e a Globalização: Impasses e perspectivas. Revista da Casa de Geografia de Sobral: Sobral, 2003. p. 131-142, V. 4/5.

BARBIERI, J. C. Gestão Ambiental Empresarial: Conceitos, Modelos e Instrumentos. São Paulo: Saraiva, 2007.

BARBIERI, J. C. ; CAJAZEIRA, J. E. R. Responsabilidade Social Empresarial e Empresa Sustentável: Da teoria à prática. São Paulo: Saraiva, 2009.

BARROCO, H. E. Uma reflexão sobre o planejamento turístico-cultural e sustentabilidade. Revista turismo \& desenvolvimento, Campinas, v.3; n.1, p. 9-16, Jan./Jun. 2004.

CÂNDIDO, L. A. Turismo em áreas naturais protegidas. Caxias do Sul: Educs, 2003.

CARDOSO, R. C; TASCHNER, G. Dimensões sociais do turismo sustentável: Estudo sobre a contribuição dos resorts de praia para o desenvolvimento das comunidades locais. São Paulo: FGV, 2005. 264f. Tese (Doutorado) - Escola de Administração de Empresas de São Paulo, Fundação Getulio Vargas, São Paulo, 2005.

CAStrogiovanNi, A. C. et al. Turismo Urbano. 2. ed. São Paulo: Contexto, 2001.

COOPER, C. et al. Turismo princípios e práticas. 3. ed. Porto Alegre: Brookman, 2007.

CORSI, E. Patrimônios histórico-culturais: uma nova perspectiva para o urbano e o rural através do turismo sustentável. Caminhos da Geografia, Uberlândia, v. 5, n.11, p 22-34, Fev. 2004.

CResWelL, J. W. Projeto de Pesquisa. Porto Alegre: Artmed, 2010.

CRUZ, L. B. Processo de formação de estratégias de desenvolvimento sustentável de grupos multinacionais. Porto Alegre: UFRGS, 2007. 444f. Tese (doutorado) Programa de Pós-Graduação em Administração, Universidade Federal do Rio Grande do Sul, Porto Alegre, 2007.

DIAS, R. Marketing Ambiental: Ética, Responsabilidade Social e Competitividade nos negócios. São Paulo: Atlas, 2008.

ENZ, C. A.; SIGUAW, J. A.; Best hotel environmental practices: Cornell Hotel and Restaurant Administration Quaterly, p. 72-77, Oct 1999.

FONS, M. V. S. et al. La sostenibilidad del turismo rural de montaña en Aragón. II Congreso internacional de turismo de montaña. Huesca, 2009.

FUNDTUR, Fundação de turismo de Mato Grosso do Sul. Perfil de Mato Grosso do Sul. Campo Grande, 2011.

GONÇALVES, L. C. Gestão Ambiental em Meios de Hospedagem. São Paulo: Aleph, 2004.

GUIMARÃES, R. P.; FEICHAS, S. A. Q. Desafios na construção de indicadores de sustentabilidade. Ambiente e Sociedade. Campinas, v. XII, n. 2, p. 307-323, Jul-dez. 2009.

HAN, H.; HSU, L.J.; SHEU, C. Application of the Theory of Planned Behavior to green hotel choice: Testing the effect of environmental friendly activities. Tourism Management, Hong Kong, v. 31, p. 325-334, Jun. 2010.

IBGE, Instituto Brasileiro de Geografia e Estatística. Economia do turismo: Uma perspectiva macroeconômica 2003-2007. Disponível em: http://www.ibge.gov.br/home/. Acesso em: 28 mar. 2011.

JAPPUR, R.F. et al. A visão de especialistas sobre a sustentabilidade corporativa frente às diversas formações de cadeias produtivas. Revista Produção On-line, Florianópolis, v. VIII, n. III, 2008.

KANAANE, R.; SEVERINO, F. R. G. Ética em Turismo e Hotelaria. São Paulo: Atlas, 2006.

MARTINS, G. A.; THEÓPHILO, C. R. Metodologia da investigação científica para ciências sociais aplicadas. São Paulo: Atlas, 2007.

MATTAR, F. N. Pesquisa de Marketing. São Paulo: Atlas, 2001. 
NASCIMENTO, L. F. Curso de graduação em administração modalidade a distância: gestão ambiental e a sustentabilidade. Florianópolis: UFSC, 2008.

NORMA BRASILEIRA. NBR 15401: Meios de hospedagem - Sistema de gestão da sustentabilidade Requisitos. Brasil, 2006.

OLIVEIRA, C. D. M; SOTTILI, D. Símbolos pantaneiros no espaço urbano de Campo Grande-MS. In: PANOSSO NETTO, A.; MARQUES, H. R. Reflexões em Turismo: Mato Grosso do Sul. Campo Grande: UCDB/ CESUR, 2004.

OMT, Organização Mundial do Comercio. Cuenta satélite de turismo (CTS): Recomendaciones sobre el marco conceptual. Nueva York; Naciones Unidas; Madrid: OMT, 2001. 149p. Disponível em: http://unstats.un.org/unsd/publication/SeriesF/SeriesF_80S.pdf. Acesso em: 16 agosto 2011.

SEVERINO, A.J. Metodologia do trabalho científico. São Paulo: Cortez, 1996.

PAULO, M. A. Um a cada dois hóspedes se preocupa com sustentabilidade hoteleira. Panoramabrasil, 20 de abril de 2011, hotelaria. Disponível em: http://www.panoramabrasil.com.br/um-a-cadadois-hospedes-se-preocupa-com-sustentabilidade-hoteleira-id62168.html. Acesso em: 23 de agosto de 2011.

RUSCHMANN, D. Turismo e Planejamento Sustentável: A proteção do meio ambiente. Campinas: Papirus, 2008.

SILVA, L. M. T.; SILVA, M. P.; ENDERS, W. T. Gestão Ambiental e Desempenho Organizacional: Um Estudo de suas Relações no Setor Hoteleiro. XXX ENANPAD - Salvador, BA, Brasil, 23 a 27 de Setembro de 2006.

SILVA, R. N.; DE CONTO, S. M. Ações ambientais em meios de hospedagem da região uva e vinho da serra gaúcha/RS. Caxias do Sul: UCS, 2007. 157 f. Dissertação (Mestrado) Programa de Pós- Graduação em Turismo, Universidade de Caxias do Sul, Caxias do Sul, 2007.

SISGRAN, Sistema Municipal de Indicadores Georreferenciados para o Planejamento e a Gestão de Campo Grande/MS. Perfil de Campo Grande. Campo Grande: SISGRAN, 2011. Disponível em: http://www.pmcg.ms.gov.br/SISGRAN/egov/imti/perfil-pageflip/egov/imti/ perfil-pageflip/index. html. Acesso em: 17 de agosto 2011.

SWARBROOKE, J.; HORNER, S. O comportamento do consumidor no turismo. São Paulo: Aleph, 2002.

TACHIZAWA, T.; ANDRADE, O.B. Gestão socioambiental: estratégias na nova era da sustentabilidade. Rio de Janeiro: Elsevier, 2008.

UNEP, United Nations Enviroment Programme. 2011. Cómo el dos por ciento del PIB mundial puede impulsar un crecimiento más verde y racional combatiendo al mismo tiempo la pobreza. Disponível em: http://www.unep.org/Documents.Multilingual/ Defauk.asp?DocumentID $=659 \&$ ArticleID $=6902 \&=$ es. Acessado em: 01 de mar.2011.

VERgARA, S. C. Projetos e Relatórios de Pesquisa em Administração. 9. ed. São Paulo: Atlas, 2007.

WTO, World Tourism Organization. Tourism and poverty alleviation: Recommendations for action. Madrid: WTO, 2004.

YIN, R. K. Estudo de Caso: Planejamento de Método. Porto Alegre: Bookman, 2005.

WTTC, World Travel \& Tourism Council. 2012. International tourism hits one billion. Disponível em: http://www.wttc.org/news-media/news-archive/2012/international-tourism-hits-one-billion/. Acesso em 11 jan. 2013.

Data de Submissão: 14/03/2012

Data de Aprovação: 06/02/2012 